Supporting Information

\title{
Cell-Type-Specific CRISPR/Cas9 Delivery by Biomimetic Metal Organic Frameworks
}

Mram Z. Alyami, ${ }^{\dagger}, \|$ Shahad K. Alsaiari, ${ }^{\dagger}, \|$ Yanyan Li,${ }^{\S}$ Somayah S. Qutub, ${ }^{\dagger}$ Fajr A. Aleisa, ${ }^{\S}$ Rachid Sougrat, $₫$ Jasmeen S. Merzaban, ${ }^{\S}$ Niveen M. Khashab ${ }^{*} \dagger$

$\uparrow$ Smart Hybrid Materials (SHMs) Laboratory, Advanced Membranes and Porous Materials Center, King Abdullah University of Science and Technology (KAUST), Thuwal 23955-6900, Saudi Arabia.

$\S$ Cell Migration and Signaling Laboratory, Division of Biological and Environmental Science and Engineering, King Abdullah University of Science and Technology (KAUST), Thuwal 239556900, Saudi Arabia.

I Advanced Nanofabrication Imaging and Characterization center, King Abdullah University of Science and Technology (KAUST), Thuwal 23955-6900, Saudi Arabia. 


\section{Materials and Methods}

\section{Materials}

All chemicals were purchased from Sigma-Aldrich and used without further purification. CRISPR associated protein 9 (Cas 9) incorporated with a nuclear localization signal (NLS). Molecular probes including (Hoechst 33342 and Alexa fluor 647), IVT sgRNA, cell counting kit-8 (CCK-8), EDTA-free mini protease inhibitor tablet and primers qRT-PCT were obtained from Thermo Fisher Scientific. The RNA extraction kit (RNeasy mini kit) and SYBR Green Master mix were provided by Qiagen. The human cervical tumor cell line (HeLa), Human breast adenocarcinoma cell (MCF-7), activated Jurkat cells (aTC) and Human Dermal Fibroblast (HDFn) were purchased from ATCC (USA). Dulbecco's Modified Eagle's Medium (DMEM), fetal bovine serum (FBS), penicillin-streptomycin, trypsin and Dulbecco's phosphate buffered saline (PBS) were purchased from Invitrogen (USA). Xenolight DiR was purchased from PerkinElmer (MA, USA).

\section{General techniques}

Dynamic light scattering (DLS) and zeta potential analyses were performed using a Malvern Nano $\mathrm{ZS}$ instrument at $25^{\circ} \mathrm{C}$ at $\mathrm{pH} 7$ in aqueous solutions. Standard deviations were calculated with three runs. Transition electron microscopy (TEM) images were recorded using a Technai $12 \mathrm{~T}$ (FEI Co.) microscope operated at $120 \mathrm{kV}$. For visualization by TEM, samples were prepared by dropping a solution of production on a copper grid 300 mesh (Electron Microscopy Sciences, LC 300-Cu). X-ray powder diffraction (PXRD) measurements were performed using a Panalytical X'Pert Pro X-ray powder diffractometer using the $\mathrm{Cu} \mathrm{K} \alpha$ radiation $(40 \mathrm{~V}, 40 \mathrm{~mA}, \lambda=1.54056 \AA)$ in a $\theta-\theta$ mode from $20^{\circ}$ to $90^{\circ}(2 \theta)$. Fluorescence data were collected using a Varian Cary Eclipse fluorimeter. Confocal laser scanning microscopy (CLSM) images were recorded using CLSM (Zeiss LSM 880 AIRYSCAN FAST System). Flow cytometry data was carried out using BD LSR-Fortessa flow cytometry. Gene expression was calculated using the Sequence Detection System software, provided by the manufacturer with a 7900HT Fast Real-Time PCR system (Applied Biosystems). 


\section{Preparation of cancer cell membrane fragments}

Cancer cell membrane fragments were prepared as previously reported with slight modification. ${ }^{1}$ Typically, Human cervix carcinoma (HeLa) cells or Human breast adenocarcinoma cell (MCF-7) cells were incubated in Dulbecco's Modified Eagle's Medium (DMEM) containing 10\% FBS and $1 \%$ antibiotics (penicillin-streptomycin). To harvest membrane, cells were grown in T-175 culture flasks to full confluency, then detached and washed in PBS three times by centrifuging at $500 \times \mathrm{g}$. The cells were suspended in a hypotonic lysing buffer consisting of $20 \mathrm{mM}$ Tris- $\mathrm{HCl} \mathrm{pH} 7.5,10$ $\mathrm{mM} \mathrm{KCl}, 2 \mathrm{mM} \mathrm{MgCl} 2$ and 1 EDTA-free mini protease inhibitor tablet per $10 \mathrm{~mL}$ of solution and disrupted using a Dounce homogenizer with a tight-fitting pestle. The entire solution was subjected to 20 passes before spinning down at 3,200 $\times \mathrm{g}$ for $5 \mathrm{~min}$. The supernatant was saved while the pellet was resuspended in hypotonic lysing buffer and subjected to another 20 passes and spun down again. The supernatants were pooled and centrifuged at $20,000 \times \mathrm{g}$ for $20 \mathrm{~min}$, after which the pellet was discarded and the supernatant was centrifuged again at 100,000 $\times \mathrm{g}$. The pellet containing the plasma membrane material was then washed once in $10 \mathrm{mM}$ Tris- $\mathrm{HCl} \mathrm{pH} 7.5$ and $1 \mathrm{mM}$ EDTA. The final pellet was collected and used as a purified cancer cell membrane for subsequent experiments.

\section{Cancer cell membrane protein characterization}

Protein characterization was conducted using sodium dodecyl sulfate-polyacrylamide gel electrophoresis (SDS-PAGE) method reported in the literature. The cracked cancer cell membrane (CCM) samples in lithium dodecyl sulfate (LDS) loading buffer (Invitrogen) CCNPs were purified by centrifugation at $18,000 \times \mathrm{g}$ to pellet the coated particles but not free vesicles or protein. Samples were heated to $90{ }^{\circ} \mathrm{C}$ for $10 \mathrm{~min}$, and $20 \mu \mathrm{L}$ of sample was loaded into each well of a NuPAGE Novex 4-12\% Bis-Tris minigel, using 3-(N-morpholino) propane sulfonic acid (MOPS) sodium dodecyl sulfate (SDS) as running buffer (Invitrogen) in an XCell SureLock Electrophoresis System based on the manufacturer's instructions. Protein staining was accomplished using Coomassie Blue (Invitrogen) and destained in water overnight before imaging. ${ }^{2}$ For western blot analysis, the protein was transferred to Protran nitrocellulose membranes (Whatman) using an XCell II Blot Module (Invitrogen) in NuPAGE transfer buffer (Invitrogen) per manufacturer's 
instructions. Membranes were probed using antibodies against histone H3 (Poly6019, Biolegend), CD44 (clone 515; BD Biosciences), E-Cadherin (clone 36; BD Biosciences) and CD49e (BD Biosciences) followed by horseradish peroxidase HRP-conjugated anti-mouse IgG (Cell Signaling) as the secondary antibody. A separate blot was prepared and stained with HRPconjugated anti-mouse IgG only as a control.

\section{Assembly of CC-ZIF}

Briefly, Cas9 and sgRNA were mixed at a molar ratio of 1:1 in a phosphate buffer saline (PBS) for $5 \mathrm{~min}$ followed by addition of 2-methylimidazole solution $(0.45 \mathrm{~mL}, 2.5 \mathrm{M}, \mathrm{pH} 7)$ for 10 minutes under mechanical agitation. An aqueous solution of zinc nitrate $(0.050 \mathrm{~mL}, 0.5 \mathrm{M})$ was then slowly added at room temperature for $20 \mathrm{~min}$, the clear solution turned opaque.

\section{Preparation of $\mathrm{C}^{3}$-ZIFs}

CC-ZIFs were prepared as previously reported with slight modification. ${ }^{1,2}$ Then, $2.0 \mathrm{~mL}$ of CCZIFs $(0.5 \mathrm{mg} / \mathrm{mL})$ were mixed with $1.0 \mathrm{~mL}$ of cracked cancer cell membrane dispersion (1.0 $\mathrm{mg} / \mathrm{mL}$ ) in deionized water. Afterward, the mixture was transferred into a syringe and successively extruded through $1.0 \mu \mathrm{m}, 800.0 \mathrm{~nm}$ and $450.0 \mathrm{~nm}$ polycarbonate membrane. The obtained $\mathrm{C}^{3}$-ZIFs NPs in solution was further purified by centrifugation to remove the free cancer cell membrane. $\mathrm{C}^{3}$-ZIFs were diluted in water for characterization or Opti-MEM medium for cell study.

\section{Cell culture}

Human breast adenocarcinoma cells (MCF-7), human cervix carcinoma (HeLa) cells, activated jurkat cells (aTC) and human dermal fibroblast (HDFn) were incubated in Dulbecco's Modified Eagle's Medium (DMEM) containing 10\% fetal bovine serum (FBS) and 1\% antibiotics (penicillin-streptomycin) at $37^{\circ} \mathrm{C}$ in a humidified atmosphere containing $5 \% \mathrm{CO}_{2}$.

\section{Cell viability}

To study cytotoxicity, cell counting kit- 8 assay (CCK-8) assay was performed according to the manufacturer's protocol. Unlabeled Cas 9 was used for the treatment. Briefly, MCF-7 cells $(5 \times$ 
$10^{3}$ cells per well) were seeded onto a 96-well plate. After 12 hours, the culture medium was changed, and cells were incubated with different concentrations $\left(150,100\right.$ and $\left.50 \mu \mathrm{g} \mathrm{mL}^{-1}\right)$ of bare ZIFs, CC-ZIFs and $\mathrm{C}^{3}$-ZIFs in $200 \mu \mathrm{L}$ of opti-MEM medium at $37^{\circ} \mathrm{C}$. Media was then discarded and a culture medium containing $10 \%$ CCK-8 solution was added into each well, including a negative control of culture media alone. After 3 hours of incubation, the absorbance was measured at $450 \mathrm{~nm}$ using a microplate spectrophotometer $\left(\right.$ xMark $^{\mathrm{TM}}$ Microplate Absorbance Spectrophotometer).

\section{Release of AF-Cas 9/sgRNA via pH trigger}

To evaluate the release of Cas 9/sgRNA from C $\mathrm{C}^{3}$-ZIF, AF 647 labeled Cas 9 was used. Aliquots of hydrochloric acid were added to $600 \mu \mathrm{g} / \mathrm{mL}$ Cas 9/sgRNA@ZIF-8@CCM in PBS to reach pH of 5. PBS only was added to the sample of $\mathrm{pH} 7$. The fluorescence of released AF-Cas 9/sgRNA was monitored by fluorescent spectroscopy (excitation/emission wavelength: $650 \mathrm{~nm} / 668 \mathrm{~nm}$ ).

\section{Homotypic targeting studies}

Flow cytometric assay (FCA), inductively coupled plasma mass spectroscopy (ICP-MS) and confocal laser scanning microscopy (CLSM) was used to investigate the homotypic targeting ability of $\mathrm{C}^{3}$-ZIFs coated with MCF-7 and HeLa cells membranes ( $\mathrm{C}^{3}-\mathrm{ZIF}_{\mathrm{MCF}}$ and $\left.\mathrm{C}^{3}-\mathrm{ZIF}_{\mathrm{HeLa}}\right)$. For flow cytometric analysis, AF 647 labeled Cas 9 (AF-Cas9) was used to track the uptake of the Cas9/sgRNA. Cells were seeded in 6 -well plates at a density of $5 \times 10^{5}$ cells per single well and cultured for $12 \mathrm{~h}$ in $2 \mathrm{~mL}$ of DMEM containing 10\% FBS and $1 \%$ antibiotics (penicillinstreptomycin). After $\mathrm{C}^{3}$-ZIF $(100 \mu \mathrm{g} / \mathrm{mL})$ was coincubated with the cells for 2 and $6 \mathrm{~h}$, then cells were washed three times with PBS, detached by trypsin and finally collected by centrifugation at $1000 \mathrm{rpm}$ for $5 \mathrm{~min}$. The bottom cells were washed three times with PBS and then the suspended cells were analyzed by flow cytometry. For confocal laser scanning microscopy observation, different cell lines have been seeded at a density of $3 \times 10^{5}$ cells per well in $1 \mathrm{~mL}$ of DMEM containing 10\% fetal bovine serum and 1\% antibiotics (penicillin-streptomycin). Incubated at 37 ${ }^{\circ} \mathrm{C}$ for $12 \mathrm{~h}$. The medium was later replaced with the fresh medium containing $\mathrm{C}^{3}$-ZIF $(100 \mu \mathrm{g} / \mathrm{mL})$. After $6 \mathrm{~h}$ coincubation, the medium was removed and the cells were washed several times with PBS. After further incubation in $1 \mathrm{~mL}$ of DMEM containing $10 \mu \mathrm{L}$ Hoechst 33342 for $15 \mathrm{~min}$ at $37^{\circ} \mathrm{C}$, the cells were photographed by CLSM. For inductively coupled plasma mass spectroscopy 
(ICP-MS) quantitatively studied, the cells were exposed to NPs without fluorescence labeling and collected following the same procedures as for flow cytometry. Collected cells were then digested by using 3:1 nitric acid and hydrogen peroxide and then diluted by deionized water up to a final concentration of $0.1 \mathrm{mg} / \mathrm{ml}$. Then, the elemental concentrations of Zinc in cells were measured by Perkin Elmer Analyst 800 ICP-MS.

\section{Generation of the enhanced green fluorescent protein (EGFP) expressing cells}

pENTR11 with the cDNA of the EGFP gene was cloned into the pDEST26 vector using Gateway® reaction (Invitrogen). Cells were maintained in MEM media (Gibco) and McCoy's media (Cellgro) supplemented with $10 \%$ FBS (Cellgro) at $37^{\circ} \mathrm{C}$ in $5 \% \mathrm{CO}_{2}$. The EGFP-construct was then transfected into HeLa and HCT116 cells (ATCC) in their respective media using a calcium phosphate method as described previously. ${ }^{3}$ In brief, cells were cultured at a density of $1.5 \times 10^{5}$ cells/mL one day before transfection in 12-well plates (Corning) using MEM media (HeLa; Gibco) or McCoy's media (HCT116; Cellgro) supplemented with $10 \% \mathrm{FBS}$ (Cellgro) at $37^{\circ} \mathrm{C}$ in $5 \% \mathrm{CO}_{2}$. The next day, the media was replaced with $1 \mathrm{~mL}$ of fresh media. In parallel $2.5 \mu \mathrm{g} / \mathrm{mL}$ of pDEST26-EGFP was mixed with $50 \mu \mathrm{L}$ of $250 \mathrm{mM} \mathrm{CaCl}_{2}$ first and then $50 \mu \mathrm{L} 2 \mathrm{X}$ HEPES buffer was added. This mixture pipetted for $\sim 30 \mathrm{~s}$ and then further incubated for another $30 \mathrm{~s}$ to allow crystals to form. The mixture of DNA containing crystals was slowly introduced to the cells in a dropwise manner and left to incubate with the cells for six hours at $37^{\circ} \mathrm{C}$. Following this incubation, the transfection mixture was removed and the cells were washed twice with PBS (Gibco). A glycerol shock was performed by adding $1 \mathrm{~mL}$ of $10 \%$ glycerol and leaving it for one minute at room temperature on the cell monolayer. Cells were then washed twice with PBS and incubated in fresh media for two days. To select stable transfectants, cells were amplified for 10-14 days and then were sorted for high GFP expression using BD Influx ${ }^{\mathrm{TM}}$ cell sorter in the KAUST Bioscience Core Lab. Stably transfected cells were expanded and used for subsequent experiments.

\section{EGFP expression assessment by flow cytometry and quantitative real-time polymerase chain reaction (qRT-PCR)}

Using a previously described method with slight modification. EGFP transfected cells were seeded in 6 wells plate at a density of $5 \times 10^{5}$ cells. Cells were cultured in RPMI medium containing 10 
$\%$ FBS and $0.1 \%$ penicillin-streptomycin at $37{ }^{\circ} \mathrm{C}$ in a humidified $5 \% \mathrm{CO}_{2}$ atmosphere. After cell

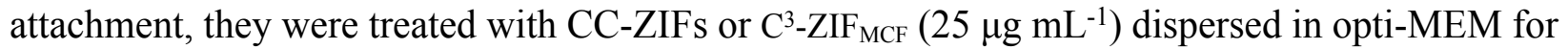
3 hours. Media containing nanoparticles was replaced by fresh RPMI media. Cells were incubated for 2 days. Finally, cells were washed and collected for flow cytometry analysis or qRT-PCR.

\section{qRT-PCR}

After washing, transfected cells were collected for RNA extraction. Total RNA was extracted using the RNeasy mini kit (Qiagen) according to the instructions of the manufacturer and total RNA concentration was calculated using Qubit. The first-strand cDNA was synthesized after the reverse transcription of the total RNA ( $2 \mu \mathrm{g})$ by using high-capacity cDNA reverse transcription kit in a $20 \mu \mathrm{l}$ reaction volume.

For RT-PCR analysis, EGFP pair of primers were used as follow: EGFP forward 5'ACGACGGCAACTACAAGACC-3', EGFP reverse 5'TTGTACTCCAGCTTGTGCCC-3'PCR regimen involved the following: $95^{\circ} \mathrm{C}$ for $20 \mathrm{~s}, 40$ cycles at $95{ }^{\circ} \mathrm{C}$ for $1 \mathrm{~s}$ and $60^{\circ} \mathrm{C}$ for $20 \mathrm{~s}$. Gene expression was calculated using the Sequence Detection System software, provided by the manufacturer with a 7900HT Fast Real-Time PCR system (Applied Biosystems).

\section{Tumor mouse model}

All the experiments were approved by the Institutional Animal Care and Use Committee (IACUC) at KAUST. MCF7 cells were prepared in HBSS at a concentration of 5x10 cells $/ \mathrm{ml}$. 6-8-weekold female or male mice were subcutaneously injected into the back of the neck with $0.2 \mathrm{~mL}$ of the preparation of MCF-7 cells $(n=12)$. Tumors were left to grown and tumor volume was frequently monitored (every 3 days) with a Vernier caliper in two dimensions until they reached a size of $100 \mathrm{~mm}^{3}$. Tumor volumes (Tv) were calculated using the formula:

$$
\mathrm{Tv}=\mathrm{ab}^{2} / 2
$$

where $\mathrm{a}$ and $\mathrm{b}$ were the largest and smallest diameters respectively. 


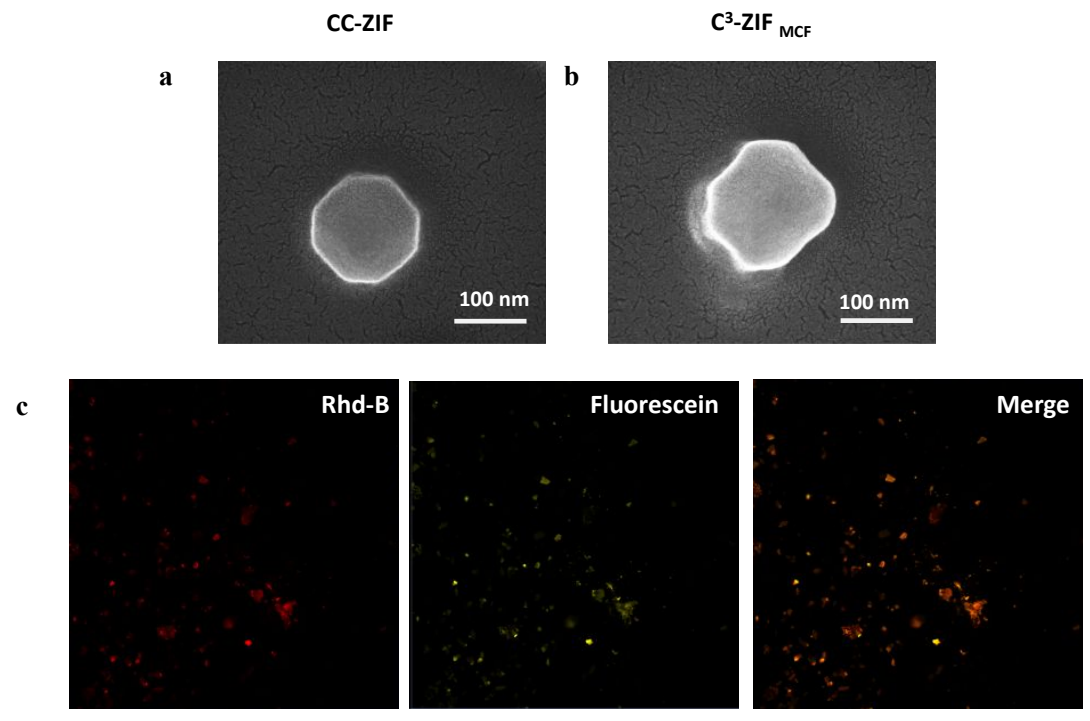

Figure S1. SEM images of CC-ZIFs before (a) and after (b) coating with MCF membrane. c) Fluorescein encapsulated ZIF-8 was coated with Rhd-B labeled CCM where the colocalization of both signals support the uniform coating. 
$\mathbf{a}$

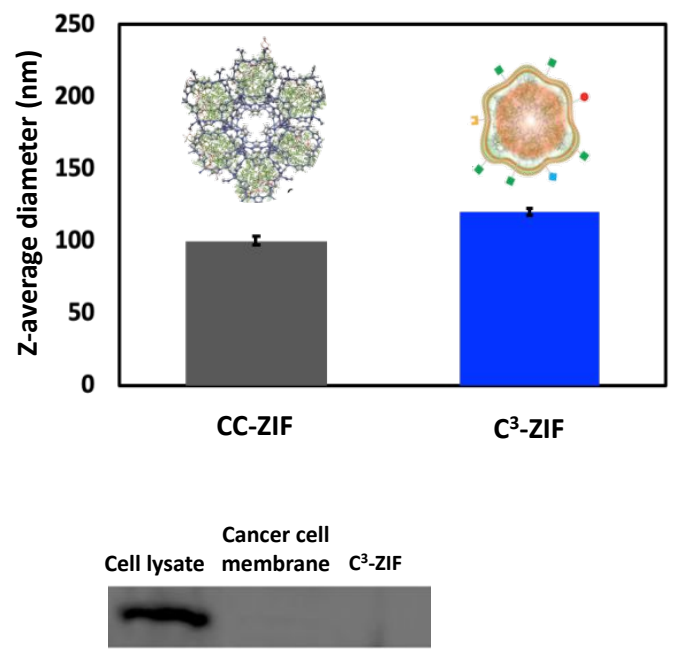

b

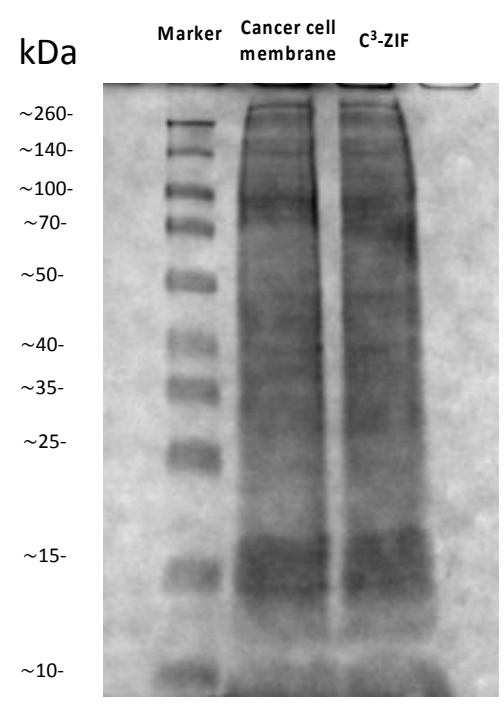

d

$\frac{\text { CD44 }}{\text { Cancer cell }_{\text {membrane }} \text { C }^{3} \text {-ZIF }}$

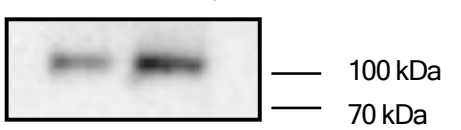

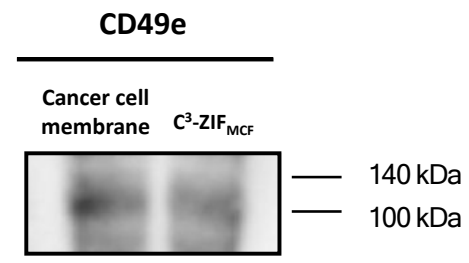

Figure S2. a) DLS size of CC-ZIF and $C^{3}$-ZIF. b) SDS-PAGE of cancer cell membrane and $C^{3}$ ZIF. c) Western blot analysis for nuclear specific marker Histone H3. d) Western blot analysis of proteins presents in cell membrane and $\mathrm{C}^{3}-\mathrm{ZIF}_{\mathrm{MCF}}$. 


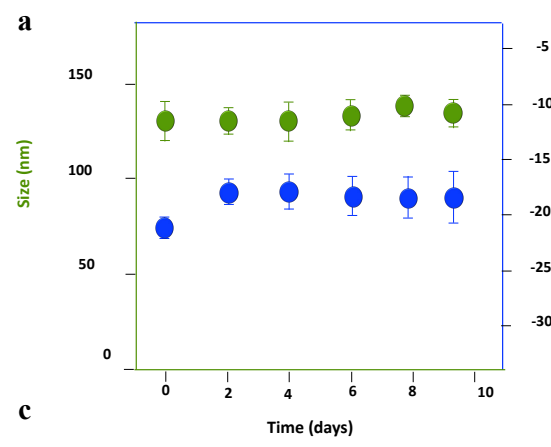

b
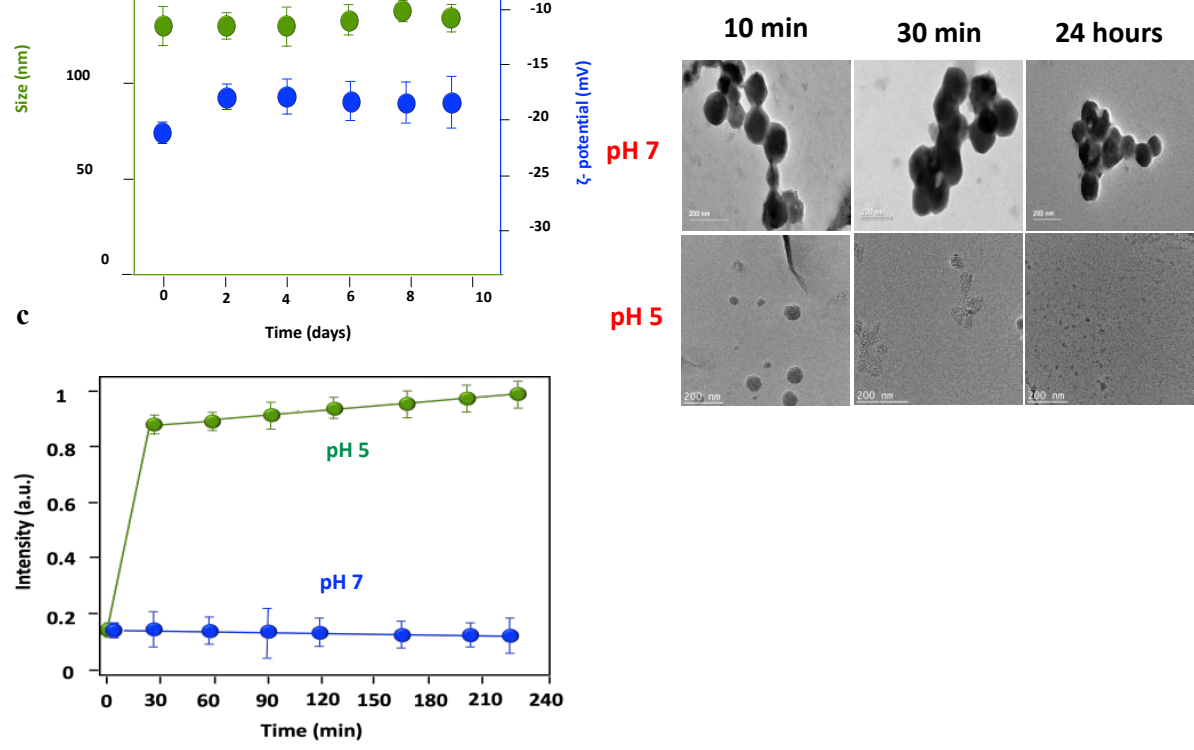

Figure S3. Stability and $\mathrm{pH}$ sensitivity of $\mathrm{C}^{3}$-ZIF. a) Evaluation of the average hydrodynamic radius and $\zeta$-Potential of the $\mathrm{C}^{3}-\mathrm{ZIF}$ at $\mathrm{pH} 7$ after 9 days. Results were expressed as mean $\pm \mathrm{SD}$ $(n=3)$. b) $\mathrm{pH}$ effect on $\mathrm{C}^{3}$-ZIF morphology and degradability. c) $\mathrm{pH}$ Dependent release of AFCas9/sgRNA from $\mathrm{C}^{3}$-ZIF. 
a

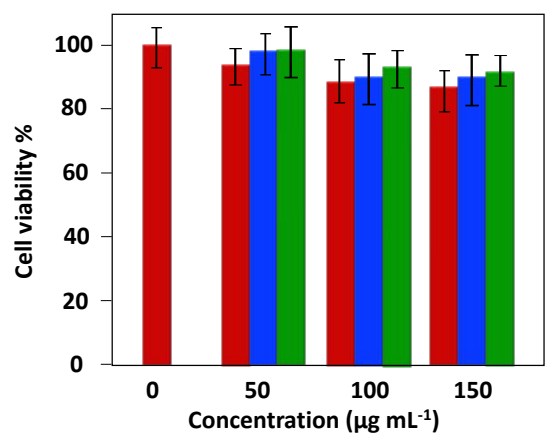

b

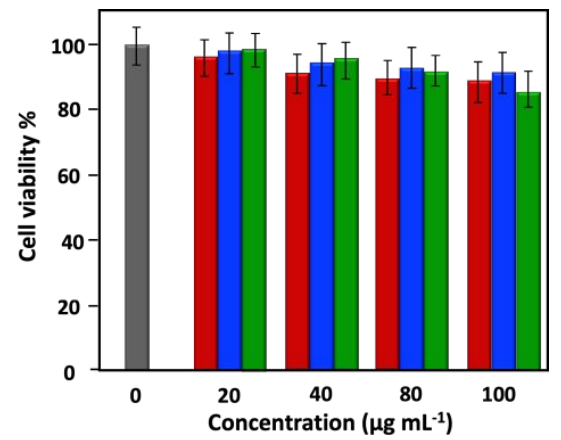

Figure S4. a) Cell viability of MCF-7 cells incubated with free ZIF (red), CC-ZIF (blue) and $\mathrm{C}^{3}$ ZIF (green). b) Cell viability of HeLa (red), aTC (blue) and HDFn (green) at different concentrations. Results were expressed as mean $\pm \operatorname{SD}(n=4)$. 

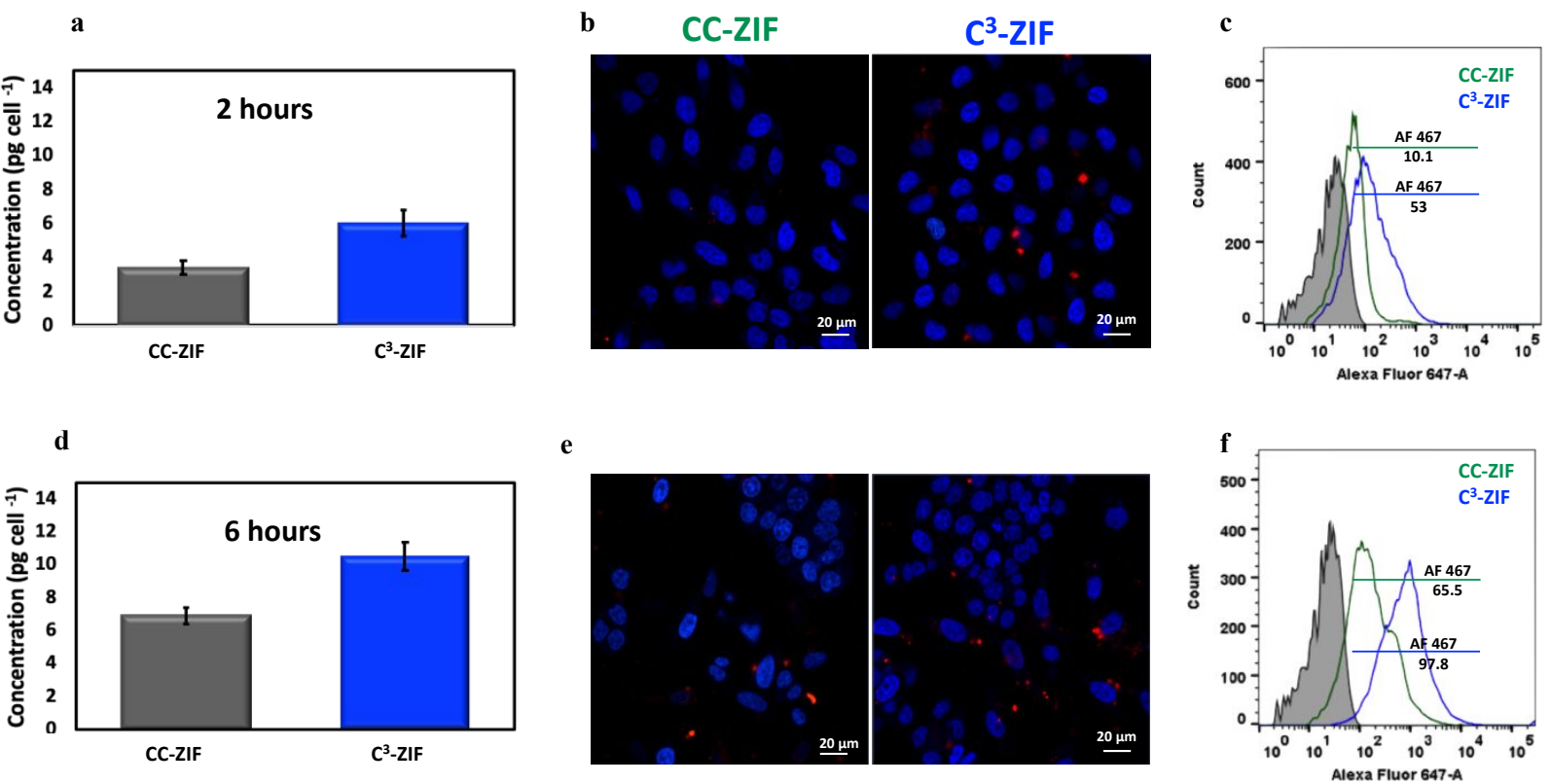

Figure S5. ICP-MS analysis of the cellular uptake of CC-ZIF and C3-ZIF incubated with MCF-7 cells for 2 and $6 \mathrm{~h}(\mathrm{a}, \mathrm{d})$. CLSM images (20×) of MCF-7 cells after incubation for 2 and $6 \mathrm{~h}(\mathrm{~b}, \mathrm{e})$. Nuclei were stained with Hoechst 33342. Scale bar: $20 \mu \mathrm{m}$. Fluorescence histogram from flow cytometric analysis from CC-ZIF (green) and C ${ }^{3}$-ZIF (blue) incubated with MCF-7 cells for 2 and $6 \mathrm{~h}(\mathrm{c}, \mathrm{f})$. 
a

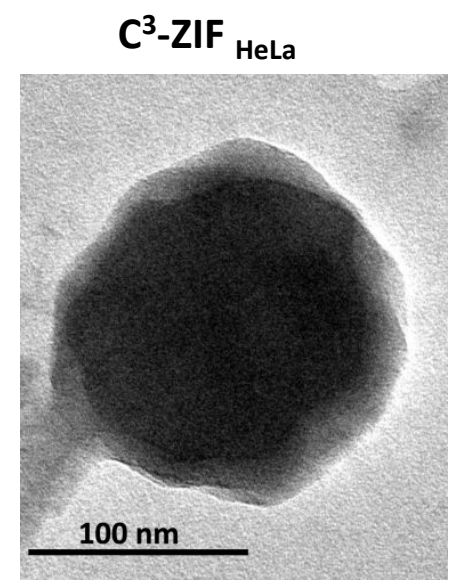

b

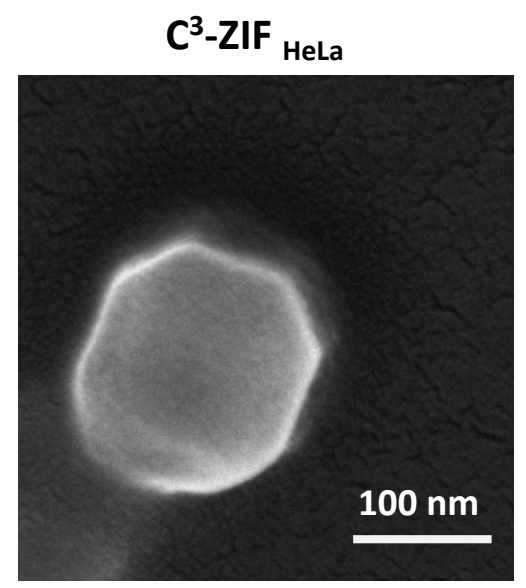

Figure S6. TEM (a) and SEM images (b) of $C^{3}-Z_{\text {IF }}$ HeLa. 
a
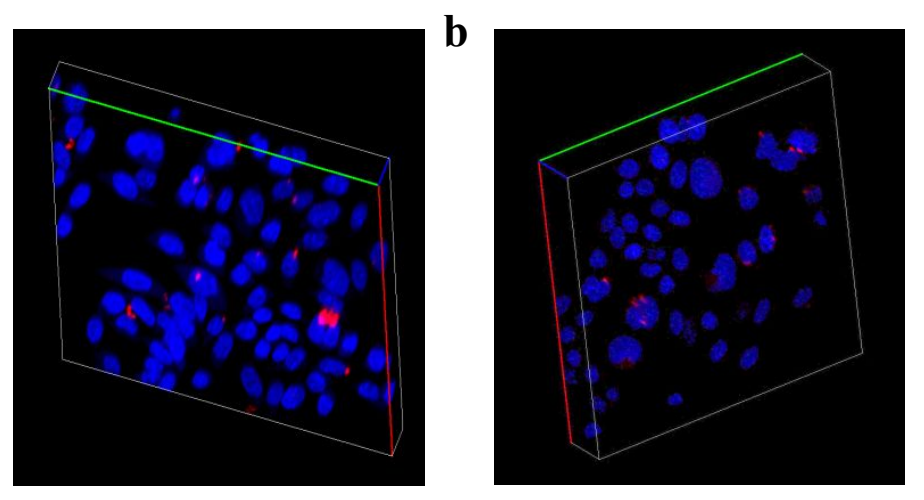

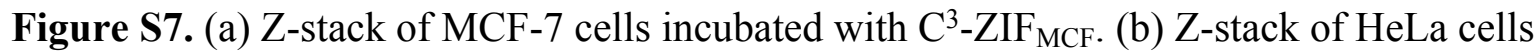
incubated with $\mathrm{C}^{3}-\mathrm{ZIF}_{\mathrm{HeLa}}$. 

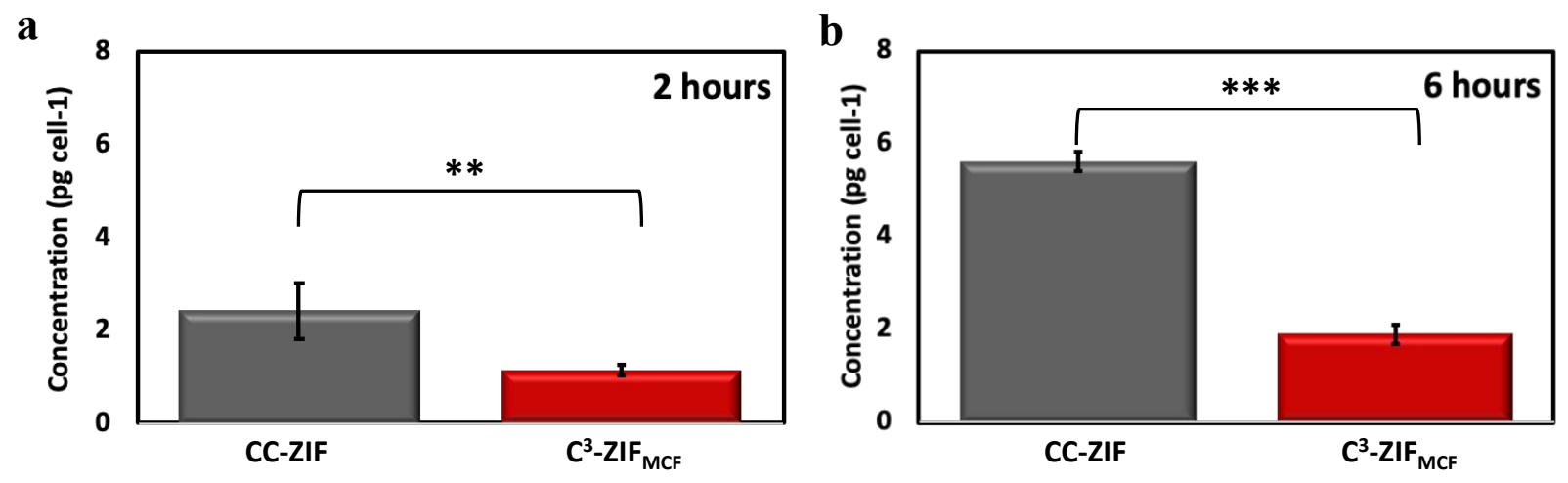

Figure S8. ICP-MS analysis of uptake of CC-ZIF and $\mathrm{C}^{3}$-ZIF by HDFn after $2 \mathrm{~h}$ (a) and $6 \mathrm{~h}$ (b) incubation. 


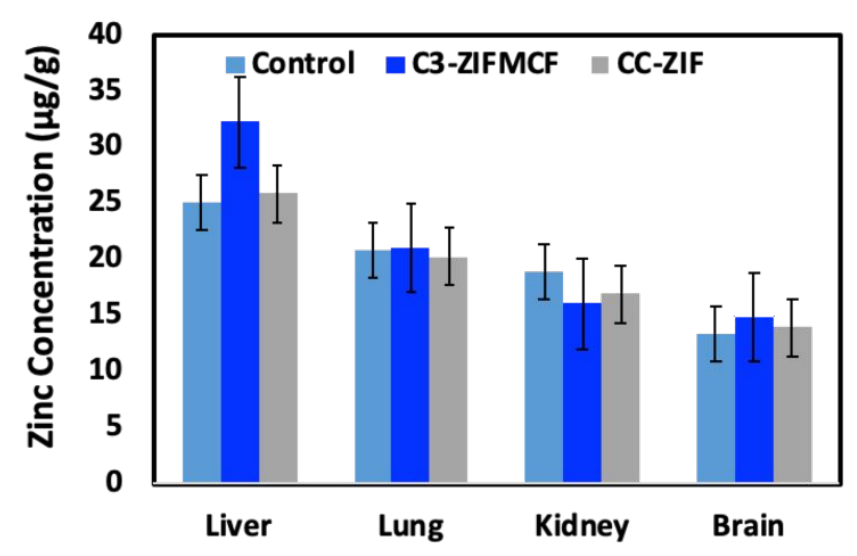

Figure 9. Nanoparticles biodistribution in mice $72 \mathrm{~h}$ after injection. A total of three samples were collected from each group. Single asterisks indicate $\mathrm{P}<0.05$, double asterisks indicate $\mathrm{P}<$ 0.01 , and triple asterisks indicate $\mathrm{P}<0.001$, respectively, as compared to control. The $\mathrm{Zn}$ concentration in liver of mice treated with $\mathrm{C}^{3}$-ZIF was slightly higher than that of the control and CC-ZIF. This is mostly attributed to the better stability/retention conferred upon the ZIF-8 by the cell membrane extract, which resulted in delaying the $\mathrm{C}^{3}$-ZIF degradation and excretion.

\section{References:}

1. $\quad$ Fang, R. H.; Hu, C.-M. J.; Luk, B. T.; Gao, W.; Copp, J. A.; Tai, Y.; O’Connor, D. E.; Zhang, L., Cancer cell membrane-coated nanoparticles for anticancer vaccination and drug delivery. Nano letters 2014, 14 (4), 2181-2188.

2. Zhu, J.-Y.; Zheng, D.-W.; Zhang, M.-K.; Yu, W.-Y.; Qiu, W.-X.; Hu, J.-J.; Feng, J.; Zhang, X.-Z., Preferential cancer cell self-recognition and tumor self-targeting by coating nanoparticles with homotypic cancer cell membranes. Nano letters 2016, 16 (9), 5895-5901.

3. Jordan, M.; Wurm, F., Transfection of adherent and suspended cells by calcium phosphate. Methods 2004, 33 (2), 136-143. 